\title{
O ENSINO JURÍDICO DA MEDIAÇÃO: UMA ABORDAGEM TRANSDISCIPLINAR
}

\author{
Keila Andrade Alves Rubiano ${ }^{1}$ \\ Frederico de Andrade Gabrich ${ }^{2}$
}

RESUMO: Com fundamento no método dedutivo e nos referenciais teóricos do CPC (Lei n. 13.105/2015), da Resolução CNJ n. 125/2010 e da Resolução MEC n. 5/2018, pretende-se analisar o direcionamento do ensino jurídico brasileiro para a melhor compreensão dos métodos consensuais de solução de conflitos, como a mediação, e a necessidade de se buscar uma abordagem transdisciplinar desta. Também aborda-se a transdisciplinaridade como possível caminho para a adequação do ensino jurídico aos novos tempos e suas rápidas transformações, bem como o respaldo jurídico normativo para essa alteração de perspectiva.

PALAVRAS-CHAVE: ensino jurídico; mediação; transdisciplinaridade; Direito; transformação.

\section{LEGAL EDUCATION OF MEDIATION: A TRANSDISCIPLINARY APPROACH}

ABSTRACT: Based on the deductive method and the theoretical references of the CPC (Law No. 13,105 / 2015), of CNJ Resolution n. 125/2010 and MEC Resolution no. 5/2018, we intend to analyze the direction of Brazilian legal education for a better understanding of consensual methods of conflict resolution, such as mediation, and the need to seek a transdisciplinary approach to it. Transdisciplinarity is also approached as a possible way to adapt legal education to the new times and its rapid transformations, as well as the normative legal support for this change in perspective.

KEYWORDS: legal education; mediation; transdisciplinarity; right; transformation.

\section{Introduçãa}

O contexto global atual é de intensa transformação no campo das relações sociais, impulsionada pelo desenvolvimento tecnológico e dos meios de comunicação. A pandemia pelo novo Coronavírus ensejou ainda maiores mudanças, pois a necessidade de isolamento

\footnotetext{
${ }^{1}$ Mestranda em Direito (Instituições Sociais, Direito e Democracia) pelo PPGD da Universidade FUMEC/MG e Analista Judiciário e Assessora de Desembargador do TRT da $3^{\text {a }}$ Região. Endereço postal: Rua Eng. Amaro Lanari, 345, Belo Horizonte/MG, CEP. 30.310-580. E-mail: keilaandradear@ gmail.com; http://lattes.cnpq.br/3986159076132725; http://orcid.org/0000-0003-2048-7373

${ }^{2}$ Doutor, Mestre e Especialista em Direito Comercial/Empresarial pela Universidade Federal de Minas Gerais. Professor Adjunto da Universidade FUMEC (BH). Endereço postal: Rua Bambuí, 355/402, Bairro Cruzeiro, Belo Horizonte/MG, CEP 30.310-320. E-mail: frederico.gabrich@ gmail.com; http://lattes.cnpq.br/9297224411224412; http://orcid.org/0000-0003-1929-2835.
} 
físico social consolidou a comunicação pelas redes sociais, a obtenção de informações e conhecimento por meio de sites de pesquisa, blogs, podcasts e diversos meios de comunicação que surgem a cada dia.

Em contraponto a tudo isso, o ensino jurídico no Brasil permanece relativamente inerte, sem grandes passos que impliquem evolução e adequação à sociedade pósmoderna, a não ser a necessária e quase obrigatória adaptação para as aulas virtuais, em razão do isolamento social e da suspensão de aulas presenciais em decorrência da pandemia pela Covid-19. Os cursos de graduação em Direito majoritariamente ainda seguem o modelo cartesiano de ensino, baseado na disciplinaridade racional. A matriz curricular e os conteúdos desenvolvidos nos cursos de graduação em Direito, com raras exceções, ainda privilegiam a transmissão do conhecimento específico de cada matéria ao aluno, que na maioria dos casos sequer é interrelacionado com as demais disciplinas do próprio curso de Direito.

O Direito, uma ciência por excelência social, clama por uma formação humanística do profissional das carreiras jurídicas, por meio da interrelação das diversas áreas do conhecimento humano, de forma inter, multi e transdisciplinar. Alguns temas atuais que envolvem o próprio Direito, como os métodos consensuais de solução de conflitos e, em especial, a mediação, exigem uma formação holística do mediador, pois asua atuação depende de conhecimentos em diversas searas, como em Direito, Psicologia e Comunicação. Todavia, grande parte das faculdades e universidades ainda não estão preparadas para esse tipo de formação, embora haja respaldo jurídico normativo para a direção de esforços no sentido da transformação necessária.

Assim, com fundamento no método dedutivo e tendo como referenciais teóricos o Código de Processo Civil - CPC (Lei n. 13.105/2015), a Resolução n. 125/2010 do Conselho Nacional de Justiça - CNJ (BRASIL, 2010) e a Resolução n. 5/2018 do Ministério da Educação - MEC (BRASIL, 2018), o presente estudo pretende analisar o ensino da mediação, como método não contencioso de solução de conflitos, dentro dos cursos de graduação em Direito, a partir de uma abordagem transdisciplinar.

Como mencionado, a linha de raciocínio adotada na pesquisa será o método dedutivo. Esse método tem o propósito de explicitar o conteúdo das premissas, das quais se extrai uma conclusão, por meio da pesquisa bibliográfica e reflexões.

Para fins do presente estudo será realizada análise crítica das seguintes questões: o ensino jurídico no Brasil e os meios não contenciosos de solução de conflitos; a 
transdiciplinaridade; o instituto da mediação; o ensino jurídico da mediação por meio da transdiciplinaridade.

\section{O ensino jurídico no Brasil e os meios não contenciosos de solução de conflitos}

O ensino jurídico no Brasil ainda segue, majoritariamente, a linha tradicional, cartesiana, que reproduz o modelo "proposto no plano filosófico por René Descartes (15961650), que pressupõe a fragmentação, a descontextualização, a simplificação, a redução, o objetivismo e o dualismo do pensar e do saber" (GABRICH, 2013). Trata-se,portanto, de um modelo baseado na disciplinaridade e na especialização, que forma profissionais com conhecimentos específicos em áreas limitadas do conhecimento jurídico.

Há, ainda, no meio jurídico, uma indiscutível cultura contenciosa, voltada para a formação de profissionais aptos a atuarem em processos judiciais, como advogados, promotores, juízes e servidores, a fim de resolverem litígios.

Todavia, conforme estabelecem os $\S \S 2^{\circ}$ e $3^{\circ}$, do artigo $3^{\circ}$, do Código de Processo Civil - CPC (Lei n. 13.105/2015):

$\S 2^{\circ}$ O Estado promoverá, sempre que possível, a solução consensual dos conflitos. $\S 3^{\circ}$ A conciliação, a mediação e outros métodos de solução consensualde conflitos deverão ser estimulados por juízes, advogados, defensores públicos e membros do Ministério Público, inclusive no curso doprocesso judicial. (BRASIL, 2015a).

O CPC, estabelece, ainda, o seguinte:

Art. 165. Os tribunais criarão centros judiciários de solução consensualde conflitos, responsáveis pela realização de sessões e audiências de conciliação e mediação e pelo desenvolvimento de programas destinados a auxiliar, orientar e estimular a autocomposição. [...]

Art. 334. Se a petição inicial preencher os requisitos essenciais e não for o caso de improcedência liminar do pedido, o juiz designará audiência de conciliação ou de mediação com antecedência mínima de30 (trinta) dias, devendo ser citado o réu com pelo menos 20 (vinte) diasde antecedência. (BRASIL, 2015a).

Não obstante, apenas recentemente, com a Portaria n. 1.351/2018 do Ministério da Educação (BRASIL, 2018), que aprovou a publicação da Resolução n. 5/2018, que instituiu as diretrizes curriculares nacionais do Curso de Graduação em Direito, as faculdades de Direito passaram a incluir, como disciplina obrigatória nas suas matrizes curriculares do curso de Direito, a Mediação, a Conciliação e a Arbitragem.

Trata-se, contudo, apenas do início de um olhar voltado para a importância da transmissão do conhecimento relativo às formas consensuais para a solução de conflitos. Como destaca Roberta de Melo Carvalho: 
No campo jurídico e, em especial nos cursos de Direito, os alunos e futuros operadores de Direito foram historicamente ensinados a litigar, a transmissão de conhecimentos não traz uma interdisciplinaridade entre Direito e Comunicação, Direito e Psicologia e os conhecimentos sobre administração e resolução de conflitos são obtidos empiricamente na atuação profissional - quando o são - e de forma viciada, litigiosa esuperficial. Revolve-se muitas vezes o processo, mas não o litígio. (CARVALHO, 2019).

É de se notar que o incentivo à adoção de outros métodos adequados para a solução de conflitos, para além do modelo judicial, ocorre nos Tribunais, de forma mais efetiva, desde a Resolução n. 125/2010 do Conselho Nacional de Justiça - CNJ, que dispõe sobre a "Política Judiciária Nacional de tratamento adequado dos conflitos de interesses no âmbito do Poder Judiciário e dá outras providências" (BRASIL, 2010). Desde então, a busca por outros meios adequados para a solução dos conflitos passou a ser tratada como uma política judiciária, definida e incentivada pelo Conselho Nacional de Justiça - CNJ. Almeja-se, assim, a implementação de um Sistema de Justiça Pacificador, que, conforme ressalta Maria Tereza Uille Gomes e Raquel Elias Ferreira Dodge, é caracterizado por uma "rede de elementos interdependentes que formam um todo organizado, em que as pessoas que integram essa rede interagem e, antes de tudo, procuram chegar a uma solução de forma pacífica. (...)" (GOMES; DODGE, 2020).

A política de ampliação das formas de solução dos conflitos encontra respaldo jurídico normativo em princípios constitucionais, como o princípio da dignidade da pessoa humana, do acesso à justiça e da duração razoável do processo e também, como explicitado acima, no Código de Processo Civil - CPC (BRASIL, 2015a). Além das regras acerca da Mediação, estabelecidas pelo CPC, a Lei n. 13.140/2015 (BRASIL, 2015b), conhecida como Lei da Mediação, define o instituto, suas regras e princípios, sendo outro importante marco legal quanto à ampliação das formas de solução (consensual) de dispostas.

O art. $6^{\circ}$ da Resolução n. 125/2010 do CNJ (BRASIL, 2010), dispõe, ainda, quecabe ao Conselho Nacional de Justiça

V - buscar a cooperação dos órgãos públicos competentes e das instituições públicas
e privadas da área de ensino, para a criação de disciplinas que propiciem o
surgimento da cultura da solução pacífica dos conflitos, bem como que, nas Escolas
de Magistratura, haja módulo voltado aos métodos consensuais de solução de
conflitos, no curso de iniciação funcional e no curso de aperfeiçoamento; (BRASIL,
2010, grifo acrescido).

O Conselho Nacional de Justiça - CNJ, por meio da referida resolução, conclama as universidades públicas e privadas, pelo menos desde 2010, a implementarem uma novadireção para o ensino jurídico, não mais voltada unicamente para o fomento de uma cultura 
contenciosa, do litígio, mas para a busca da solução pacífica dos conflitos.

Contudo, o desafio é enorme e vai muito além da eficácia das normas jurídicas estabelecidas no ordenamento, pois pressupõe o rompimento do modelo cartesiano e tradicional de ensino jurídico - voltado quase que exclusivamente para a solução judicialde conflitos - e a construção de uma cultura da paz e da estruturação jurídica eficiente dos objetivos das pessoas (naturais e jurídicas), preferencialmente sem conflitos e com uso de meios consensuais para a composição de interesses eventualmente conflitantes. Isso exige uma visão estratégica do Direito e a valorização de um ensino jurídico inter, multi e transdisciplinar.

\section{O que vem a ser a transdisciplinaridade?}

Em um mundo em acelerada transformação no campo social, tecnológico e dosmeios de comunicação, faz-se premente uma análise holística do conhecimento e da ciência, com a integração as ideias e do conhecimento de forma plural, aberta e transdisciplinar.

De fato, a transdisciplinaridade pressupõe uma visão aberta e pluralista do conhecimento, que busca, por meio da correlação das várias áreas do conhecimento (acadêmico ou não), a unificação do saber, em uma amplitude não alcançável quando conhecimento é fracionado racionalmente em um encadeamento sistemático de disciplinas.

Eduardo Sieno Wiviurka ressalta que, embora a transdisciplinaridade não se trate de uma hiperciência e, nem tampouco, numa ciência das ciências,

(...) há a defesa da existência de uma unidade da ciência que ocorre pela comunicação e articulação entre a pluralidade de campos de pesquisa, estabelecendo uma verdadeira teia, na qual cada disciplina mantém sua autonomia, mas participa de uma unidade maior que representa o sistema complexo. Todas as disciplinas que almejam realizar uma pesquisa transdisciplinar, devem contextualizar-se neste sistema articulador das áreas do conhecimento, no qual, em última instância, todas as áreas do conhecimento se comunicam-se - direta ou indiretamente - com todas as demais. Somente assim opera-se a transcendência do reducionismo, abrindo uma ponte para o método transdisciplinar. (WIVIURKA, 2010).

Realmente, para se compreender a transdisciplinaridade, é importante entender os conceitos da pesquisa disciplinar, interdisciplinar, multidisciplinar e transdisciplinar. Disciplina "é uma área delimitada do conhecimento científico, tendo um objeto determinado e frequentemente isolado de seu contexto, uma linguagem própria com termos com carga semântica peculiar a sua área (...)” (WIVIURKA, 2010). No caso da pesquisa interdisciplinar, por outro lado, realiza-se a ligação entre duas ou mais disciplinas, relativizando a soberania 
de cada uma delas, de modo a se formar um novo campo de pesquisa, como é o caso, por exemplo, da biofísica e da bioética. Já a pesquisa multidisciplinar ou pluridisciplinar ocorre quando é necessária a soma de esforços científicos de diversas áreas para se explicar um fenômeno complexo sob enfoques diferentes (WIVIURKA, 2010).

Não há dúvidas da relevância de todo o conhecimento científico já alcançado, por meio da pesquisa focada em áreas específicas. Todavia, nenhum desses métodos de pesquisa (disciplinar, interdisciplinar e multidisciplinar) é capaz de desenvolver um pensamento holístico, alcançando a efetiva interrelação das áreas do conhecimento científico e não científico. Como destaca Frederico de Andrade Gabrich, "a interdisciplinaridade pressupõe a transferência de métodos de pesquisa e de prática de uma disciplina para a outra, em um processo de análise essencialmente analógico.” (GABRICH, 2013). Destaca, ainda, o autor que:

De fato, a transdisciplinaridade subverte toda a lógica do pensamento cartesiano clássico, pois, segundo este, não há nada entre, através e/ou além das disciplinas. Além disso, de acordo com a lógica tradicional, não pode existir uma disciplina sem objeto determinado.

A transdisciplinaridade desconsidera tudo isso, bem como a lógica piramidal e fundamentalmente evolutiva do conhecimento. Como se não bastasse, a transdisciplinaridade não considera que cada disciplina tenha um campo de sua pertinência inesgotável. Como ressaltado acima, a transdisciplinaridade não élinear e pressupõe a conjunção de todos os saberes, contextualizados a partir das necessidades reais das pessoas e da vida. Na transdisciplinaridade o pensare o ensinar pressupõem a importância de todos os modos de conhecimento, detodas as culturas, religiões, ideias e ciências que convivem e se complementam continua e sistematicamente em vários níveis de realidade. (GABRICH, 2013).

Quando se fala em transdisciplinaridade busca-se, portanto, uma formação mais humana, holística e crítica, permitindo-se uma maior adequação à complexidade crescente do mundo pós-moderno. Trata-se, assim, de "um enfoque pluralista do conhecimento que tem como objetivo, através da articulação entre as inúmeras faces de compreensão do mundo, alcançar a unificação do saber.” (INFOESCOLA, 2020).

O mundo atual, em que as relações sociais são cada vez mais complexas e interligadas, clama por esse olhar múltiplo e integrado do saber, por um movimento de reflexão que ultrapassa a linha de um conhecimento específico. Nesse sentido, exige-se dos profissionais, das mais diversas áreas, um olhar para o horizonte, aberto a integração com outras áreas do conhecimento; um saber multifacetário e dinâmico.

Um olhar transdisciplinar para o ensino jurídico pode, assim, ser o caminho para concatenação de novas realidades com o ensino, bem como para a adequada formação donovo 
profissional do Direito, apto a integrar um mercado de trabalho diferente do tradicional e muito mais dinâmico (GABRICH, 2013).

Os métodos consensuais de solução de conflitos também exigem esse olhar e essa formação holística e transdisciplinar, especialmente na Mediação. É preciso, assim, que o ensino jurídico propicie uma interrelação entre o Direito e a Comunicação, o Direito, as artes e a literatura, o Direito e a Administração, bem como entre o Direito e aPsicologia, a fim de se possibilitar, como destaca o art. 6, $\mathrm{V}$, da Resolução 125/2010 do CNJ (BRASIL, 2010), o surgimento de uma cultura de solução pacífica dos conflitos, inter, multi, transdisciplinar, significativa e efetiva.

\section{A mediação para a solução de conflitos}

Algumas áreas de conhecimento exigem, por sua própria origem, esse olhar multifacetário, dinâmico e transdisciplinar. É o caso dos métodos consensuais para a solução de conflitos, em especial a Mediação.

A Mediação "é um mecanismo utilizado como caminho para resolução de conflitos desde comunidades primitivas passando pelas modernas e difundida na contemporaneidade" (COELHO; BONATO, 2018). Na década de setenta do século XX, a Mediação passou a ser adotada nos Estados Unidos da América, de forma pré-processual, a fim de reduzir o número de processos ajuizados e possibilitar uma melhor atuação do Poder Judiciário (COELHO; BONATO, 2018).

No Brasil, a Resolução n. 125/2010 do CNJ (BRASIL, 2010) implementou a Política Judiciária Nacional de tratamento adequado dos conflitos de interesses no âmbito do Poder Judiciário, que caminha em uma direção mais dialógica com os vários atores sociais na construção de uma política de administração da justiça, voltada efetivamente para a pacificação social. Trata-se de importante marco na busca da ampliação dos meiosadequados para a solução de conflitos, sem afastar do jurisdicionado a certeza dapossibilidade de acesso ao Poder Judiciário, a quem cabe o papel de retaguarda, conferindo segurança jurídica às relações sociais, dentro de um estado democrático deDireito.

A Lei 13.140/15 (BRASIL, 2015b) regulamentou o instituto da Mediação no Brasil. O parágrafo único do art. $1^{\circ}$ dessa norma dispõe que a Mediação é uma "a atividade técnica exercida por terceiro imparcial sem poder decisório, que, escolhido ou aceito pelas partes, as auxilia e estimula a identificar ou desenvolver soluções consensuais para a controvérsia." 
(BRASIL, 2015). Esse terceiro neutro e imparcial atua como mero facilitador do diálogo, para que as próprias partes "construam, com autonomia e solidariedade, a melhor solução para o conflito. Em regra, é utilizada em conflitos multidimensionais ou complexos" (BRASIL, 2016).

A relevância da Mediação para a solução consensual (extrajudicial ou judicialmente) de determinados conflitos é cada vez mais aceita pela doutrina. Constitui instrumento de expressão da cidadania, por representar meio capaz de sustentar as bases de um convívio social calcado no valor da justiça (MELLO, 2017).

A Mediação vem da escuta das partes, atuando o terceiro (mediador) como facilitador do diálogo, sendo relevante para casos específicos e delicados, que envolvem sentimentos, ressentimentos e angústias, e que muitas vezes ficam mascaradas no processo e que sequer transparecem perante o Estado-juiz (SCHMIDT, 2016).

Como leciona Martha Halfeld Furtado de Mendonça Schmidt, acerca da Mediação:

Aplicar-se-ia ela em regra a casos "subjetivados", em que há prevalência de emoções, mesmo que subjacentes à formalidade da ação judicial. Para a mediação importa menos o resultado do acordo - que, se alcançado, é reconfortante para todos -, do que o alívio do sofrimento vivenciado pelas partes no curso do processo de mediação. Trata-se, portanto, de um enriquecimento da resposta judicial, que não é aplicável a todos os casos, mas àqueles em que se discutem interesses afetivos ou aos casos considerados difíceis, nos quais são debatidos vários aspectos jurídicos, sendo necessária ponderação de valores e interesses - os denominados "hard cases", cujo risco de interpretações díspares pode variar substancialmente. (SCHMIDT, 2016).

De acordo com o art. $2^{\circ}$ da Lei n. 13.140/2015 (BRASIL, 2015b), a Mediação é orientada pelos seguintes princípios: imparcialidade do mediador; isonomia entre as partes; oralidade; informalidade; autonomia da vontade das partes; busca do consenso; confidencialidade e boa-fé.

Ao discorrerem a respeito dos princípios que devem nortear a conduta do mediador, Terezinha Lima de O. Rocha e Cleide Rocha de Andrade destacam a imparcialidade; a decisão informada; o empoderamento e a competência.

Alguns princípios são norteadores da conduta do mediador: a imparcialidade -
entendida como o cuidado em não emitir nenhum julgamento de valor, a
confidencialidade dos conteúdos expressos pelas partes, a voluntariedade da
participação, ou seja, a mediação só ocorrerá se as partes consentirem
espontaneamente; a decisão informada - que diz respeito à plena consciência das
pessoas quanto aos seus Direitos e a realidade fática na qual se encontram; o
empoderamento, no sentido de que as partes em disputa possam, cada vez mais, por
si mesmas, resolver seus futuros conflitos recorrendo à experiência de justiça
vivenciada na autocomposição; a competência, traduzida na exigência de
capacitação obrigatória e continuada. (ROCHA; ANDRADE, 2016, p. 219).

Revista de Pesquisa e Educação Jurídica | e-ISSN: 2525-9636 | Encontro Virtual | v. 7 | n. 1 | p. 01 - 17 | Jan/Jul. 2021. 
A mediação se apresenta, portanto, como uma ferramenta eficaz de comunicaçãoe de solução de conflitos. Ela tem por objetivo o desenvolvimento da capacidade de diálogo entre as partes, para que busquem soluções para seus propósitos divergentes. Permite, ainda, uma reflexão maior de todos os envolvidos no conflito, acerca da melhormaneira de se relacionar.

(...) a mediação vem sendo apresentada como uma proposta transformadora do conflito, já que não busca a solução por um terceiro, mas, sim, a solução pelas próprias partes que recebem o auxílio do mediador para administrá-la. A mediação não se preocupa com o litígio, nem com a verdade formal contida nos autos e nem tem como finalidade a obtenção do acordo; visa a ajudar as partes a redimensionar os problemas, e o mediador exerce a função de ajudar as partes a reconstruírem a relação conflituosa. (MELLO, 2017, p. 29).

Para que a Mediação seja eficaz, todavia, o mediador deve deter conhecimentos e habilidades que permitam a confiabilidade das partes e a compreensão dos caminhos a serem perseguidos. Por consequência, a formação do mediador depende de um entrelaçamento de habilidades e saberes, científicos e não científicos, que envolve, por exemplo, a empatia, o respeito às diferenças, a capacidade de saber ouvir, a experiência de vida, bem como o Direito, a Psicologia, a Comunicação, a Sociologia etc.

\section{A mediação, a transdisciplinaridade e o ensino jurídico}

A atuação do mediador exige primordialmente a comunicação com as partes envolvidas no conflito e tem por objetivo propiciar que elas percebam os fatos por novos ângulos, transformando aquilo que pensam. Para essa finalidade, é necessária umaformação transdisciplinar do mediador, a fim de que ele possa lidar com aspectosmultifacetados, auxiliando as pessoas envolvidas para que elas próprias construam a solução do conflito, por meio do diálogo e de negociações.

(...) o mediador precisará contar com uma soma de saberes decorrentes de uma formação interdisciplinar que o habilitará a trafegar na complexidade das interações humanas, a atuar com estratégias de negociação e servir-se de um modelo de comunicação não-violenta que o permita ajudar as pessoas a conversarem de modo que cada qual ajude a outra a compreender efetivamenteo que é dito por elas.

Com efeito, tal formação interdisciplinar implica na aprendizagem de múltiplos conhecimentos e deve buscar a integração e interação das disciplinasna composição do campo de formação teórica do mediador que reunirá tais saberes para nortear sua atuação transdisciplinar. As disciplinas estudadas contemplam os aspectos psíquicos, filosóficos e sociais dos conflitos, abrangem as teorias de comunicação e linguagem, recorrem às teorias estratégicas de negociação contidas nos livros de Fisher e Ury e comportam oestudo de diversas técnicas de condução de conflitos. (ROCHA; ANDRADE,2016, p. 220).

De fato, nessa perspectiva, o(a) mediador(a) precisa ter conhecimentos disciplinares, 
inter, multi e transdisciplinares, que permitam a ele(a), por exemplo, por meio da hermenêutica dos símbolos (semiótica), das metáforas (inclusive artísticas), do storytelling, provocar o pensamento, o autoconhecimento e a reflexão crítica das partes envolvidas, sem que isso implique interferência do(a) mediador(a) na tomada de decisão, ou na escolha da solução decorrente da mediação.

Nesse sentido, a transdisciplinaridade ganha força no estudo da mediação, pois ela representa essa mistura de conhecimentos, que implica o uso complexo de diversos saberes (científicos ou não) e de diversas disciplinas. Nesse sentido, atransdisciplinaridade encontrase no estudo teórico e empírico das diversas disciplinas, por meio das práticas transdisciplinares, que mesclam esses diversos saberes em um mesmo campo de ação (COELHO; BONATO, 2018).

A formação transdisciplinar do mediador implica, portanto, múltiplos conhecimentos interrelacionados, a partir de uma formação teórica e prática de saberes, habilidades e disciplinas, que abranjam diversas áreas como por exemplo: Filosofia, Psiquiatria, Psicologia, Sociologia, Comunicação e Direito. Essa formação transdisciplinar e holística do mediador é imprescindível para que ele tenha efetivas condições de lidar com todas as vicissitudes das situações que envolvem o conflito e o comportamento humano.

A Psicologia "possibilita a compreensão da importância das emoções e dos afetos" (COELHO; BONATO, 2018). É a Psicologia que permite "perceber as motivações, os desejos, a passionalidade e os afetos intricados nas posições, argumentações e atitudes dos mediandos" (COELHO; BONATO, 2018).

Saulo Versiani Penna e Gina Chaves ressaltam que "a interdisciplinaridade entre Direito e Psicanálise propicia que o indivíduo deixe de ser visto como objeto do Direito, e passe a sujeito de Direito, o que favorece a comunicação entre as partes e, com isso, a construção dialética da solução dos conflitos de interesse" (PENNA; CHAVES, 2017, p. 165). Essa capacidade de escuta, para compreensão dos dilemas subjacentes aos conflitos, a fim de ser resgatada a comunicação entre os envolvidos, depende de técnicas, que a Psicologia pode dotar o mediador. Nesse sentido, Roberta de Melo Carvalho pontua que:

o problema, muitas vezes, está na incapacidade do exercício da escuta ativa pelo profissional de Direito. Ouvir e interpretar o que o outro diz, sabendo extrair suas necessidades leva o operador de Direito a um campo vastíssimo de possibilidades de solução daquela questão trazidapor seu cliente. Pelo contrário, com a mente aberta e a preparação técnica para outros meios de solução de conflito, o operador do Direito pode encontrar a solução de forma mais célere e efetiva, alcançando, assim, maior satisfação do cidadão que o procura. (CARVALHO,2019). 
É preciso compreender que o Direito e a Psicologia, embora tenham como campos importantes de atuação o conflito, possuem metodologias distintas. Enquanto o Direito analisa o conflito de forma racional, compreendendo o indivíduo jurídico como um sujeito detentor de autonomia da vontade, capaz de reger seus próprios atos, a Psicologia busca compreender o conflito a partir de uma análise subjetiva e íntima do indivíduo (PENNA; CHAVES, 2017). Assim, apesar de a Psicanálise e do Direito seremcomplementares, "a primeira se baseia na escuta analítica, enquanto o segundo está assentado em sua função decisória” (PENNA; CHAVES, 2017, p. 167).

Nesse contexto, a Psicologia, no campo da mediação, tem por finalidade a compreensão do indivíduo, de modo a entender o motivo subjacente ao conflito de interesses, contribuindo para que as partes envolvidas encontrem caminhos para a pacificação. Assim complementam Saulo Versiani Penna e Gina Chaves, que:

É nesse aspecto oculto dos procedimentos judiciais que a escuta analítica,
incorporada ao Direito pela sua interdisciplinaridade com a Psicanálise, permite o
conhecimento dos dilemas internos, instrumentalizando o Judiciário a, realmente,
solucionar os dilemas subjacentes ao conflito jurídico manifestado. (PENNA;
CHAVES, 2017, p. 172).

Por seu turno, tratando-se a Mediação de um meio comunicacional, as teorias da comunicação permitem que o mediador compreenda a dinâmica do conflito, pois:

\begin{abstract}
por meio da fala dos mediandos, da linguagem corporal destes, a forma como se comunicam uns com os outros e, por fim trata da necessidadede trabalhar os canais de comunicação para que estejam abertos e que não haja ruídos na comunicação entre os contendores do conflito. (COELHO; BONATO, 2018).
\end{abstract}

O que se percebe, portanto, é que quanto mais eclético, experiente, global e holístico for o conhecimento do mediador, melhor será a sua atuação e contribuição para solução dos conflitos que lhe são apresentados. Essa constatação fica evidenciada quando se tem em conta que a Mediação é um método consensual de solução de disputas aplicável e efetivo em diversas áreas do Direito, como, por exemplo, no Direito de Família, no Direito Empresarial (societário) e no Direito do Trabalho. Nesse sentido, vários tipos de conflitos podem ter uma solução pela Mediação, como aqueles decorrentesde problemas relativos a: pensão alimentícia, guarda dos filhos, divórcio, partilha de bens, acidentes de trânsito, dívidas em bancos, fixação de indenizações decorrentes de danos materiais e morais, demissão do trabalho, questões de vizinhança, apuração de haveres dos sócios, determinação de responsabilidade de administradores e dos sócios controladores, exclusão de sócios etc. 
É preciso, portanto, que o ensino jurídico volte o seu olhar para esse clamor poruma cultura da autocomposição e da pacificação social. Sem deixar de lado a formação técnica do profissional do Direito, que o capacite para atuar judicialmente em processos, é necessária uma abertura de pensamento, a fim de afastar a enraizada cultura do litígio e de sua solução judicial. Para isso, o profissional do Direito precisa ser devidamente preparado, não apenas para a atuação em processos judiciais, mas para a estruturação jurídica eficiente dos objetivos das pessoas (naturais e jurídicas) e, no bojo dela, a previsão da solução consensual (preferencialmente extrajudicial) de eventuais conflitos decorrentes de falha da estratégia desenvolvida, sobretudo por meio da conciliação e da Mediação. Para isso, dentre outros conhecimentos e habilidades, é absolutamente necessária a compreensão da importância que transdisciplinaridade pode ter para a maior eficiência e eficácia dos meios alternativos para a solução de conflitos (com destaque paraa Mediação).

Nesse sentido, é importante destacar que a Resolução n. 5/2018 do Ministério da Educação (BRASIL, 2018), que institui as diretrizes curriculares para o Curso de Graduação em Direito, em seu art. $5^{\circ}$, dispõe que o projeto pedagógico do curso de graduação em Direito, dentre outros elementos estruturais, deve abranger a inter e a transdisciplinaridade, bem como o estudo dos meios alternativos para a solução consensual dos conflitos. Assim:

Art. $5^{\circ}$. O curso de graduação em Direito, priorizando a interdisciplinaridade e a articulação de saberes, deverá incluir no PPC, conteúdos e atividades que atendam às seguintes perspectivas formativas:

I - Formação geral, que tem por objetivo oferecer ao graduando os elementos fundamentais do Direito, em diálogo com as demais expressões do conhecimento filosófico e humanístico, das ciências sociais e das novas tecnologias da informação, abrangendo estudos que, em atenção ao PPC, envolvam saberes de outras áreas formativas, tais como: Antropologia, Ciência Política, Economia, Ética, Filosofia, História, Psicologia e Sociologia;

II - Formação técnico-jurídica, que abrange, além do enfoque dogmático, o conhecimento e a aplicação, observadas as peculiaridades dos diversos ramos do Direito, de qualquer natureza, estudados sistematicamente e contextualizados segundo a sua evolução e aplicação às mudanças sociais, econômicas, políticas e culturais do Brasil e suas relações internacionais, incluindo-se, necessariamente, dentre outros condizentes com o PPC, conteúdos essenciais referentes às áreas de Teoria do Direito, Direito Constitucional, DireitoAdministrativo, Direito Tributário, Direito Penal, Direito Civil, Direito Empresarial, Direito do Trabalho, Direito Internacional, Direito Processual; Direito Previdenciário, Formas Consensuais de Solução de Conflitos; e

III - Formação prático-profissional, que objetiva a integração entre a prática e os conteúdos teóricos desenvolvidos nas demais perspectivas formativas, especialmente nas atividades relacionadas com a prática jurídica e o TC.

Revista de Pesquisa e Educação Jurídica | e-ISSN: 2525-9636 | Encontro Virtual | v. 7 | n. 1 | p. 01 - 17 | Jan/Jul. 2021. 
$\S 1^{\circ}$ As atividades de caráter prático-profissional e a ênfase na resoluçãode problemas devem estar presentes, nos termos definidos no PPC, de modo transversal, em todas as três perspectivas formativas.

$\S 2^{\circ} \mathrm{O}$ PPC incluirá as três perspectivas formativas, consideradosos domínios estruturantes necessários à formação jurídica, aosproblemas emergentes e transdisciplinares e aos novos desafios deensino e pesquisa que se estabeleçam para a formação pretendida. (BRASIL, 2018). (grifo nosso).

Como se não bastasse, a mesma Resolução n. 5/2018 do MEC, em seu artigo $8^{\circ}$ estabelece o seguinte:

Art. $8^{\circ}$ As atividades complementares são componentes curriculares que objetivam enriquecer e complementar os elementos de formação doperfil do graduando, e que possibilitam o reconhecimento da aquisição, pelo discente, de conteúdos, habilidades e competências, obtidas dentro ou fora do ambiente acadêmico, que estimulem atividades culturais, transdisciplinares e inovadoras, a critério do estudante, respeitadas as normas institucionais do curso. (BRASIL, 2018).

A Resolução n. 5/2018 do MEC (BRASIL, 2018) confere às faculdades de Direito a possibilidade, portanto, de integração das diversas áreas do conhecimento ao ensino jurídico, de modo a se alcançar uma melhor formação humanística dos juristas, inclusive por meio da transdisciplinaridade e da Mediação.

Para que tudo isso seja realidade no ensino do Direito, Frederico de Andrade Gabrich destaca, que:

\begin{abstract}
Na prática do ensino jurídico, então, a imposição da transdisciplinaridade pode significar a realização conjunta de aulas, palestras, pesquisas e artigos científicos, nos quais o diálogo entre as diversas disciplinas e entre os diversos conhecimentos (formais ou não, tais como os saberes culturais que são transmitidos de geração para geração) deve acontecer pela divisão do "palco" entre os mais diversosprofessores e alunos. Essa prática deve considerar o conhecimento científico preexistente, mas também a combinação deste com os sentimentos e com as individualidades das pessoas para as quais ciência se destina. Nada mais natural então, de acordo com essa lógica transdisciplinar, que os professores das diversas disciplinas e dos diversos cursos de uma mesma universidade - ou até mesmo de universidades distintas - realizem, pelos menos uma ver por semestre, um rodízio de turmas e de cursos, permitindo a livre circulação do saber, sem as amarras geralmente estabelecidas pela forma, pelos nomes das disciplinas e cursos, pelas verdadeiras e literais "grades" curriculares. (GABRICH, 2013).
\end{abstract}

Há, portanto, respaldo normativo e meios para a adoção de uma visão transdisciplinar na elaboração das matrizes curriculares dos cursos de graduação em Direito.

Especificamente em relação à Mediação, vale destacar, com a vigência da Portaria $n$. 1.351/2018 do Ministério da Educação (BRASIL, 2018), passou a ser obrigatória a inclusão da disciplina Mediação, Conciliação e Arbitragem nas matrizes curriculares do curso de graduação Direito.

De fato, o passo à frente pode ser iniciado não apenas pela disciplina específicasobre

Revista de Pesquisa e Educação Jurídica | e-ISSN: 2525-9636 | Encontro Virtual | v. 7 | n. 1 | 
Mediação, Conciliação e Arbitragem, mas, o que seria melhor, também por meio de uma abordagem transversal, inter e transdisciplinar dos mesmos temas, independentemente da existência da disciplina específica, o que exige, entretanto, uma orientação específica do Projeto Pedagógico do Curso, bem como o aprimoramento da formação e da narrativa desenvolvidas pelos coordenadores e por todos os professores dos cursos de Direito que adotarem tal perspectiva transversal, inter e transdisciplinar da Mediação.

\section{Conclusão}

A partir da Resolução n. 125/2010 do Conselho Nacional de Justiça - CNJ (BRASIL, 2010), a busca por outros meios adequados para a solução dos conflitos passoua ser tratada como uma política judiciária, definida e incentivada pelo Conselho Nacionalde Justiça - CNJ. Essa resolução, em seu art. $6^{\circ}, \mathrm{V}$, conclama as instituições públicas e privadas da área de ensino a criação de disciplinas que propiciem o surgimento da culturada solução pacífica dos conflitos. A solução consensual dos conflitos, também consta como princípio de orientação do Estado na composição de interesses, como denota o disposto no Código de Processo Civil (Lei n. 13.105/2015).

Isso, contudo, somente é possível se ampliados os horizontes do ensino jurídico, deixando de lado o tradicional ensino cartesiano e fragmentado (com foco na atuação judicial e adversarial), para se buscar uma formação estratégica, holística, multifacetáriae dinâmica do estudante e do futuro profisssional do Direito, por meio da valorização daestruturação jurídica eficiente dos objetivos das pessoas, da pacificação social, da autocomposição, da inter, multi e da transdisciplinaridade. A Resolução n. 5/2018 do Ministério da Educação (BRASIL, 2018), que institui as diretrizes curriculares para o Curso de Graduação em Direito, prevê a integração de diversas áreas do conhecimento ao ensino jurídico, de modo a se alcançar uma formação humanística, inovadora, inter, multi e transdisciplinar dos juristas, voltada também para a solução extrajudicial e consensual dos conflitos.

Com a vigência da Portaria n. 1.351/2018 do Ministério da Educação (BRASIL,2018) e da Resolução n. 5/2018 do Ministério da Educação (BRASIL, 2018), passou a ser obrigatória nas matrizes curriculares do curso de graduação em Direito, a inclusão de disciplina relacionada às Formas Consensuais de Solução de Confltios, como a Mediação, a Conciliação e a Arbitragem,.

Todavia, a inovação, a inter e a transdisciplinaridade são também diretrizes 
estabelecidas pelo Ministério da Educação para os cursos de graduação em Direito. E a transdisciplinaridade pressupõe a integração de todos os conhecimentos, ideias e ciências,sem a necessidade de formação de uma disciplina específica para esse fim. Essa necessidade de conjunção dos saberes se mostra ainda mais evidente em relação aos métodos de solução extrajudicial de conflitos, como, por exemplo, a Mediação, que exige do profissional que atua nessa área habilidades pessoais e conhecimentos, científicos ou não, em diversos campos do saber.

Assim, os cursos de graduação em Direito devem incluir em suas matrizes a disciplina específica sobre Mediação, a Conciliação e a Arbitragem, mas também, por meio de uma abordagem inovadora, transversal, inter, multi e transdisciplinar, desenvolver os mesmos temas relativos à solução consensual e extrajudicial dos conflitosdurante todo o curso, em todas as disciplinas. Mas isso exige uma orientação específica do Projeto Pedagógico do Curso, bem como o aprimoramento da formação e das narrativas desenvolvidas pelos coordenadores e por todos os professores dos cursos de Direito que adotarem tal perspectiva transversal, inter, multi e transdisciplinar.

Faz-se, mister, assim, que as faculdades de Direito encampem essa ideia e busquem esse novo olhar para o ensino jurídico, a fim de atenderem à invocação do Conselho Nacional de Justiça, prevista no art. $6^{\circ}$ da Resolução n. 125/2010 do CNJ (BRASIL, 2010), no sentido de que a instituições públicas e privadas da área do ensino contribuam para o surgimento de uma cultura de solução pacífica de conflitos. A transdisciplinaridade e a Mediação, certamente, são caminhos viáveis para se alcançaressa finalidade.

\section{REFERÊNCIAS}

BRASIL. Conselho Nacional de Justiça. Manual de Mediação Judicial. Brasília. DF.2016. Disponível em: https://www.cnj.jus.br/wpcontent/uploads/2015/06/f247f5ce60df2774c59d6e2dddbfec54.pdf. Acesso em: 27 jan. 2021.

BRASIL. Conselho Nacional de Justiça (CNJ). Resolução n. 125, de 29 de novembrode 2010. Brasília, DF, 2010. Disponível em: https://www.cnj.jus.br/wpcontent/uploads/2011/02/Resolucao_n_125-GP.pdf. Acesso em: 28 dez. 2020.

BRASIL. Lei 13.105, de 16 de março de 2015. Código de Processo Civil. Brasília, DF, Senado, 2015. Disponível em: http://www.planalto.gov.br/ccivil_03/_ato20152018/2015/lei/113105.htm. Acesso em: 28 dez. 2020. 
BRASIL. Lei 13.140, de 26 de junho de 2015. Brasília, DF, Senado, 2015. Disponível em: http://www.planalto.gov.br/ccivil_03/_ato2015-2018/2015/Lei/L13140.htm. Acessoem: 28 dez. 2020.

BRASIL. Ministério da Educação e Cultura (MEC). Portaria n. 1.351, de 14 de dezembro de 2018. Brasília, DF, 2018. Disponível em:

bmes.org.br/arquivos/legislacoes/PORTARIA\%20n_1351.pdf. Acesso em: 28 dez. 2020.

BRASIL. Ministério da Educação e Cultura (MEC). Resolução CNE/CES n. 9, de 29de setembro, de 2004. Brasília, DF, 2004. Disponível em:

http://portal.mec.gov.br/cne/arquivos/pdf/ces092004Direito.pdf. Acesso em: 27 de jan.2021.

BRASIL. Ministério da Educação e Cultura (MEC). Resolução n. 5, de 17 dedezembro, de 2018. Brasília, DF, 2018. Disponível em: https://www.in.gov.br/materia/-

/asset_publisher/Kujrw0TZC2Mb/content/id/55640393/do1-2018-12-18-resolucao-n-5- de-17de-dezembro-de-2018-55640113. Acesso em: 26 de fev. 2021.

CARVALHO, Roberta de Melo. CEJUSC/JT: Uma nova realidade, um novo caminho: análise dos avanços e perspectivas da política pública de conciliação em âmbito trabalhista. Revista do Tribunal Regional do Trabalho da 10ª Região. Brasília, DF, v. 23, n. 2, 2019.

COELHO, Washington Souza; BONATO, Giovanni. A mediação no contexto atual: um caminho para o diálogo transdisciplinar. Revista de Formas Consensuais de Solução de Conflitos. Salvador, v. 4, p. 144/165, jan/jun. 2018. Disponível em: https://www.indexlaw.org/index.php/revistasolucoesconflitos/article/view/4442/pdf. Acesso em: 27 jan. 2021.

GABRICH, Frederico de Andrade. Transdisciplinaridade no ensino jurídico. In: XXII Encontro Nacional CONPEDI, 2013, Curitiba. Direito, educação, ensino e metodologia jurídicos. Florianópolis: FUNJAB, 2013. v. 1. P. 372-387. Disponível em: http://www.publicaDireito.com.br/artigos/?cod=57db7d68d5335b52\#: :text=A\%20tran sdisciplinaridade\%20no\%20ensino \%20jur\%C3\%ADdico,de\%20organiza\%C3\%A7\%C 3\%A3o\%20social\%20e\%20de. Acesso em: 27 jan. 2021.

GOMES, Maria Tereza Uille Gomes; DODGE, Raquel Elias Ferreira. Sistema de Justiça Pacificador e os 15 anos do Conselho Nacional de Justiça: Passado, Presente eInovações Futuras do Judiciário. Revista Eletrônica CNJ. Brasília, v. 4, n. 1, jan/jul 2020. Disponível em: www.cnj.jus.br. Acesso em: 28 dez. 2020.

INFOESCOLA. Transdisciplinaridade. Disponível em: https://www.infoescola.com/educacao/transdisciplinaridade/. Acesso em: 27 jan. 2021.

MELLO, Grasielle dos Reis Rodrigues. A mediação como oportunidade de transformação sociojurídica. In: CAMPOS, Andréa Vasconcelos; ALBUQUERQUE, Judith Euchares Ricardo de; SCHMIDT, Martha Halfeld Furtado de; PEREIRA, Rita Andréa Guimarães de Carvalho (Coords.). Diálogos entre Direito e Psicanálise: umaabordagem contemporânea. Belo Horizonte: RTM, 2017.

Revista de Pesquisa e Educação Jurídica | e-ISSN: 2525-9636 | Encontro Virtual | v. 7 | n. 1 | p. 01 - 17 | Jan/Jul. 2021. 
PENNA, Saulo Versiani; CHAVES, Gina. Psicanálise e Mediação: uma construção dialética da solução do conflito de interesse no Direito de família. In: CAMPOS, Andréa Vasconcelos; ALBUQUERQUE, Judith Euchares Ricardo de; SCHMIDT, Martha Halfeld Furtado de; PEREIRA, Rita Andréa Guimarães de Carvalho (Coords.). Diálogos entre Direito e Psicanálise: uma abordagem contemporânea. Belo Horizonte:RTM, 2017.

ROCHA, Terezinha Lima de O.; ANDRADE, Cleide Rocha de. Mediação de conflitosno campo judicial e interdisciplinaridade: "O mundo não é perfeito". In: SOUZA, Cláudia Maria Gomes de; JAYME, Fernando Gonzaga; SCHMIDT, Martha Halfeld Furtado de Mendonça; PEREIRA, Rita Andréa Guimarães de Carvalho (Coords.).

Mediação de conflitos: a emergência de um novo paradigma. Belo Horizonte: Del Rey,2016.

SCHMIDT, Martha Halfeld Furtado de Mendonça. Mediação judicial trabalhista e promoção de Direitos fundamentais. In: SOUZA, Cláudia Maria Gomes de; JAYME, Fernando Gonzaga; SCHMIDT, Martha Halfeld Furtado de Mendonça; PEREIRA, RitaAndréa Guimarães de Carvalho (Coords.). Mediação de conflitos: a emergência de umnovo paradigma. Belo Horizonte: Del Rey, 2016.

WIVIURKA, Eduardo Sieno. A transdisciplinarização do Direito. Anais do XIX Encontro Nacional do CONPEDI. Conselho Nacional de Pesquisa e Pós-graduação em Direito (CONPEDI). Florianópolis, SC, 2010. Disponível em: http://www.publicaDireito.com.br/conpedi/manaus/arquivos/anais/fortaleza/3278.pdf, Acesso em: 27 jan. 2021. 